rev.relac.int.estrateg.segur.10(1):111-131,2015

\title{
RELACIONES ENTRE ESPAÑA Y AMÉRICA LATINA EN EL ÁMBITO DE LA DEFENSA*
}

\author{
Mariano César Bartolomé**
}

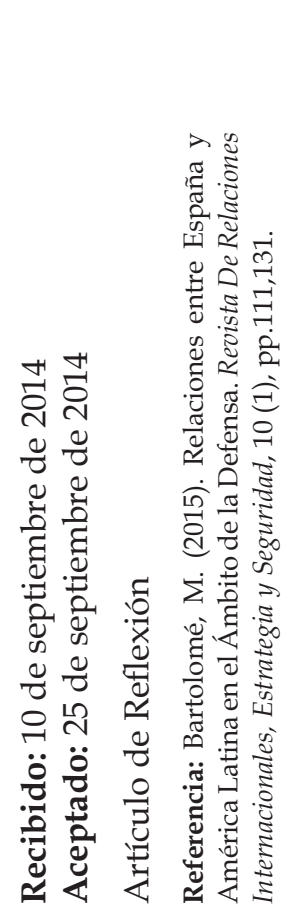

\section{RESUMEN}

El presente trabajo se enmarca en las relaciones existentes entre España y América Latina, ámbito en el cual se registra una continua presencia latinoamericana dentro de los objetivos prioritarios de la política exterior española. En ese contexto se insertan las vinculaciones bilaterales en materia de Defensa, observándose que en ese plano Madrid ha implementado diferentes formas de vinculación con la contraparte. Nuestro objetivo es aportar información sobre las relaciones entre España y América Latina en materia de Defensa, encuadradas conceptualmente en una Diplomacia de Defensa. Con esa meta, en primer lugar se efectuará un breve repaso sobre las relaciones desarrolladas entre las partes en los últimos tiempos, para luego enmarcar en ese

El presente artículo se desprende del proyecto de investigación "Vinculaciones internacionales entre América Latina y España en materia de Defensa" (código 33B123), Programa de Investigación "Amílcar Herrera", Secretaría de Ciencia y Técnica de la Universidad Nacional de Lanús (UNLa), Argentina.

** Graduado y Doctor en Relaciones Internacionales. Profesor Titular e Investigador en la Universidad Nacional de Lanús (UNLa). Profesor Titular en la Universidad del Salvador (USAL). 
plano las acciones de la Diplomacia de Defensa. Luego se analizan en detalle dos expresiones de ese despliegue: la comercialización de material de Defensa de procedencia española en el mercado latinoamericano y el empleo del instrumento militar en el marco de iniciativas multilaterales que involucren a la contraparte. Finalmente, en el apartado de conclusiones se evaluará lo actuado y las opciones a futuro que ofrece el campo de la Defensa, para las relaciones entre España y América Latina.

Palabras clave: América Latina, Defensa, Diplomacia de Defensa, España, Fuerzas Armadas.

\title{
RELATIONS BETWEEN SPAIN AND LATIN AMERICA IN THE FIELD OF DEFENSE
}

\begin{abstract}
This paper is framed in the relations between Spain and Latin America, where the continuous presence in that region is registered as preeminent goals of the Spanish foreign policy. In this context the bilateral relations related to the Defense area are inserted. As we can consider, Madrid has implemented different ways to be related with its counterpart. Our goal is to provide information on the relations between Spain and Latin America in the Defense field, conceptually framed in a Defense Diplomacy. With this objective, in the first place a brief review on the relations developed between the actors concerned during the last years will be carried on in order to frame in that context the actions of the Defense Diplomacy. Second, two expressions of that deployment will be analyzed: the commercialization of the Spanish defense material in the Latin American market and the employment of the military instrument in the frame of multilaterals initiatives that involves the counterpart. Finally, during the conclusions and evaluation on the actions took will be done and the options that the defense field offers for the future involving Spain and Latin American relations will be analyzed.
\end{abstract}

Keywords: Armed Forces, Defense, Defense Diplomacy, Latin America, Spain.

\section{RELAÇÕES ENTRE ESPANHA E AMÉRICA LATINA NO ÂMBITO DA DEFESA}

\section{RESUMO}

Este trabalho se enquadra nas relações entre a Espanha e a América Latina, uma área onde a presença latino-americana permanente é observada no âmbito das prioridades da política externa espanhola. Neste contexto são inseridas as relações bilaterais em matéria de Defesa, e em neste plano, Madrid programou diferentes formas de envolvimento com a contraparte. Nosso objetivo é fornecer informações sobre a relação entre a Espanha e a América Latina 
no domínio da Defesa, conceitualmente enquadrada numa Diplomacia da Defesa. Com esta finalidade, em primeiro lugar será fornecida uma breve visão geral das relações desenvolvidas entre as partes nos últimos tempos, e depois colocadas, neste contexto, as ações da Diplomacia da Defesa. Em seguida, serão analisadas em detalhe duas expressões dessa implantação: a comercialização de equipamento militar de origem espanhola no mercado latino-americano, e o uso do poder militar no âmbito de iniciativas multilaterais que envolvam a contraparte. Por fim, na seção final são avaliados os processos e opções para o futuro que oferece o campo da Defesa, para as relações entre a Espanha e a América Latina.

Palavras-chave: América Latina, Defesa, Diplomacía da Defesa, Espanha, Forças Armadas.

\section{INTRODUCCIÓN}

Puede observarse que, más allá de matices y particularidades asociadas al período que se tome en cuenta, se registra una continua presencia de América Latina dentro de los objetivos de la política exterior española. Esa presencia invita a indagar sobre el verdadero rol que desempeña en la actualidad el espacio latinoamericano en la política externa peninsular y cuáles son las formas de expresión del vínculo bilateral. Nuestro énfasis en las cuestiones de la Defensa lleva a especificar ese interrogante, razón por la cual nos cuestionamos si tales asuntos ocupan algún lugar relevante dentro de los esquemas de vinculación entre España y América Latina.

Al respecto, la información disponible es escasa y fragmentaria, siendo notoria la ausencia de trabajos latinoamericanos que abarquen esta temática. El presente artículo pretende contribuir a la superación de ese pernicioso estado de cosas y a responder la pregunta planteada anteriormente, indicando que por parte de Madrid se han implementado en el ámbito de la Defensa diferentes vías de vinculación con las naciones de la contraparte.

El documento se estructura en tres partes: la presente introducción, un desarrollo y finalmente las conclusiones. La fase de desarrollo se iniciará con un breve repaso sobre las relaciones entre España y América Latina en los últimos tiempos, para luego abordar en detalle sendas manifestaciones de ese vínculo en el ámbito de la Defensa, como expresiones de una Diplomacia de Defensa que se conceptualiza de acuerdo a la documentación oficial española.

\section{CARACTERÍSTICAS DEL VÍNCULO ESPAÑA - AMÉRICA LATINA}

Históricamente, debido a un íntimo vínculo de naturaleza histórica y cultural, España le ha otorgado importancia a América Latina en el contexto de su política exterior. Esta orientación se ha mantenido inalterable a lo largo de las últimas décadas, a despecho de otras variaciones registradas en la agenda de los asuntos externos de España, asociadas a cambios regimentales 
o influencias ideológicas. Como bien indica el catedrático Calduch Cervera, una constante de la política exterior española ha sido el desarrollo de las relaciones con las naciones de su comunidad histórica, existiendo consenso en que Iberoamérica pertenece a esa comunidad (Calduch Cervera, 2002).

A partir del inicio de la transición democrática española en 1976 la política exterior empezó a ser objeto de atención creciente en ese país, incluyendo una dimensión clave de la misma, la política iberoamericana. No sólo por razones identitarias y afinidades históricas, lingüísticas y culturales, sino también por causas económicas y sociales, ésta ha sido objeto de una mayor consideración.

Marcelino Oreja, ministro de Asuntos Exteriores entre los años 1976 y 1980, señaló que la creciente importancia que adquirieron en esos momentos América Latina, el Mediterráneo y el Medio Oriente dentro de la política exterior española, estuvo enmarcada en un previo anclaje de Madrid en las instituciones europeas. Se decía en esos momentos que era desde su pertenencia a Europa, como España podía aumentar su influencia, presencia y capacidad de ayuda en regiones que, como América Latina, eran prioritarias en materia de política exterior.

En ese marco, en los años ochenta la política exterior española prestó especial respaldo a los procesos de democratización en América del Sur y a la pacificación de los conflictos armados internos en Centroamérica. El panorama cambió en la década siguiente; en ese período, ya con las democracias generalizadas en América Latina, el énfasis del accionar hispano se orientó al desarrollo económico, y también al apoyo a sus movimientos de integración (Fundación Carolina, 2011). Conviene tener presente que a partir del referido decenio, la apertura y desregulación de los aparatos productivos de numerosas naciones latinoamericanas propició cuantiosas inversiones de capitales peninsulares, buena parte de ellas en las áreas de servicios públicos.

Entonces desde mediados de los años ochenta y a causa de su ingreso en la Comunidad Europea, la relación de España con América Latina buscó alinearse con la del resto del Viejo Continente para intentar, desde la coincidencia y convergencia, ejercer posiciones de liderazgo en la política europea hacia América Latina. Esta iniciativa ha sido interpretada como el intento de ejercer un rol de puente entre las partes comunitaria y latinoamericana (Grasa Hernández, 2001).

El compromiso político español con la región latinoamericana siguió vigente en el presente siglo y se ha dicho que América Latina constituye un área permeable al ejercicio del status de potencia media que pretende ese país y cuya ejecución efectiva reforzaría la imagen internacional de Madrid (del Arenal, 2004). Sin embargo, es justo decir que en los años inmediatamente posteriores a los atentados terroristas perpetrados en Nueva York y Washington en septiembre de 2001, el vínculo entre España y América Latina sufrió los efectos negativos del alineamiento del gobierno de José María Aznar con Washington respecto a la invasión a Irak, al tiempo que los gobiernos latinoamericanos no acompañaban a su vecino septentrional en esa acción militar ni en los foros multilaterales. 
Le cupo al gobierno de José Luis Rodríguez Zapatero mejorar ese vínculo y hacia fines de la primera década del presente siglo, coincidiendo con el bicentenario de la independencia de numerosas naciones latinoamericanas, el grueso de las fricciones de los años anteriores parecían superadas. En ese sentido el canciller español Miguel Ángel Moratinos calificó a América Latina como el espacio natural de la política exterior española, lo que parecía sustentarse también en números: la región concentraba más de un tercio de su cooperación y una cuarta parte de sus inversiones (Gratius, 2010).

A inicios de la presente década, desde la titularidad del ministerio de Asuntos Exteriores español se ratificó una vez más que su política exterior cobra valor por su relación privilegiada con América Latina, siendo que no se puede entender España como país y como sociedad, si no es en relación a América Latina, porque ahí está una parte de su identidad. Todo esto complementado por nuevos desafíos, entre ellos el de la globalización: España ya no es un país que se relaciona de manera bilateral, sino que lo hace a partir de su integración con el conjunto de las naciones de la Unión Europea (Fundación Carolina, 2011); como ya se ha visto, este posicionamiento constituía en realidad la reafirmación de un lineamiento con más de dos décadas de vigencia.

En el marco de su involucramiento en los asuntos latinoamericanos, España propicia el diseño y articulación de mecanismos de cooperación bi o multilaterales sobre una vasta gama de temas que incluye, en un listado no exhaustivo, el desarrollo económico-social; la consolidación y optimización de instituciones democráticas; la convergencia de posiciones sobre asuntos globales y la resolución pacífica de controversias, entre otros. Al momento de pasar revista a esos mecanismos se constata que los mismos incluyen la cooperación en materia de Defensa, entendida ésta en un sentido amplio.

Esta inclusión es comprensible, si se tiene en cuenta que uno de los ámbitos en los que se mueve el sector Defensa es en lo referente a compromisos estratégicos vinculados con el interés del Estado (García Covarrubias, 2005); además, las Fuerzas Armadas modernas son entendidas como vía de comunicación y herramienta de cooperación interestatal, razón por la cual los vínculos entre Estados en materia de Seguridad y Defensa trascienden la esfera de lo estrictamente castrense para contribuir al fortalecimiento general de las relaciones bilaterales e, inclusive, a la exportación y promoción de valores (Aznar, 2012).

En esta línea las cuestiones de la Defensa, especialmente aquellas vinculadas al instrumento militar, son susceptibles de contribuir a un interés directo del Estado español, más allá del partido o grupo que transitoriamente ocupe el Poder Ejecutivo en Madrid, que consiste en ampliar y consolidar sus vínculos con (e influencia sobre) las naciones latinoamericanas.

Un trabajo en este sentido (Michou y Torreblanca, 2013) alude a las Tres D que integran actualmente la conducta externa de los Estados (Diplomacia, Desarrollo y Defensa), agregando que España ha aplicado de manera efectiva esa integración en ocasión de los procesos de 
construcción de paz en América Central en los años 80, en el conflicto de Yugoslavia y en Afganistán en la última década.

De acuerdo a especialistas, la cooperación entre España y las naciones iberoamericanas en materia de Defensa es sustantiva, aunque está lejos de colmar siquiera mínimamente las posibilidades existentes. En este sentido, se ha dicho (Chinchón Álvarez, 2007) que las potencialidades de la cooperación en enseñanza/formación militar en el caso de España no encuentran un grado de aprovechamiento ni tan siquiera cercano a lo actuado por Francia o el Reino Unido y, por supuesto, quedan muy lejos de la intensa actividad desplegada en este ámbito por los EE.UU.

En la última década esta situación comenzó a cambiar. La Directiva de Defensa Nacional (DDN) 1/2004 de España señaló específicamente: "Iberoamérica constituye otra área preferente para España. La política de defensa intensificará las relaciones bilaterales y, en su caso, de cooperación militar. Igualmente, apoyaremos las iniciativas regionales encaminadas a reforzar la cooperación multilateral entre los países de la Comunidad Iberoamericana". Este documento oficial incluyó a Iberoamérica dentro de lo que se denomina Área de Especial Interés, por sus implicaciones en cuanto al abastecimiento de recursos energéticos y por la especial vinculación histórica, cultural y política con la Madre Patria (Fuente Cobo, 2007).

Esta postura se ratificó con la implementación de una nueva Directiva de Defensa Nacional en el año 2008, actualmente vigente. Bajo el título Vocación Iberoamericana la página oficial de la cartera de Defensa española aborda los contenidos de ese documento, citando textualmente: "Nuestro país mantiene una relación especial con Iberoamérica, constituyendo el puente natural de unión e intercambio entre las dos orillas del Atlántico. Desde esta posición, España seguirá promoviendo en materia de política de defensa la intensificación de las relaciones de cooperación bilaterales, regionales y multilaterales"1.

Precisamente en esa DDN se hace mención oficial al concepto de Diplomacia de Defensa, que ayuda a comprender la lógica de esas intenciones de la política exterior hispana. Sobre este concepto, se ha indicado que es diferente de la diplomacia tradicional y agrupa actividades diversas, no todas de naturaleza estrictamente militar, orientadas al logro de un entorno internacional estable y pacífico donde puedan alcanzarse los objetivos nacionales.

El Ministerio de Defensa de España ha identificado cinco fines específicos para orientar su actividad diplomática (Ministerio de Defensa, 2011). En primer lugar, fomentar el conocimiento, entendimiento y confianza recíprocos sobre cuestiones propias de ese ámbito con países

1. "Vocación Iberoamericana". Página web oficial del Ministerio de Defensa de España, s/f. Disponible en http://www. defensa.gob.es/politica/seguridad-defensa/contexto/iberoamericana/ 
relevantes para la acción exterior del Estado; segundo, contribuir a instaurar y consolidar un orden global estable mediante la cooperación en materia de Defensa; en tercer término, contribuir al control y prevención de conflictos mediante el respaldo a los procesos de consolidación del estado de Derecho en el ámbito de la Defensa; cuarto, desarrollar dentro de un marco jurídico adecuado, relaciones de diálogo y cooperación en materia de Defensa con naciones vinculadas histórica y culturalmente a España; y en último lugar, fomentar el despliegue de la industria española, como medio de favorecer su capacidad tecnológica y comercial.

La diplomacia de Defensa que despliega España de cara a América Latina tiene múltiples manifestaciones, entre ellas la comercialización de material de Defensa y la coparticipación en iniciativas multilaterales con empleo del instrumento militar, que a continuación se detallan. Existen, cabe aclarar, otros espacios de cooperación que escapan a los alcances del presente trabajo, como la educación y las actividades científicas en la Antártida, por citar solamente dos de ellos.

\section{LA COMERCIALIZACIÓN DE MATERIAL DE DEFENSA}

Dentro del rango de potencias medianas, el desarrollo español en materia de industrias para la Defensa es notable, con importantes productos autóctonos y un significativo grado de avance tecnológico. Aunque ese desarrollo reposa en buena medida en la actividad privada, el Estado juega un destacado papel como orientador de esas acciones, a través de la Estrategia de Tecnología e Innovación que desenvuelve la cartera de Defensa.

Entre las metas que persigue esa estrategia se incluyen el logro de un mejor posicionamiento de las actividades de contenido tecnológico alrededor de los objetivos ministeriales específicos; la obtención de las capacidades necesarias para la Defensa y el fomento a la interacción entre los diferentes agentes nacionales que desarrollan y proveen tecnología para el área (Méndez, 2013).

La industria hispana para la Defensa adquirió un claro perfil exportador, alcanzando un importante posicionamiento en el mercado internacional de comercialización de equipamiento de ese rubro, en lo que va del corriente siglo. En el año 2012, el último ejercicio completo registrado a los efectos del presente trabajo, más del $67 \%$ de los ingresos generados por la industria de la Defensa española tuvieron su origen en mercados externos y fueron materializados por ochenta empresas en más de sesenta países. Esos logros fueron alcanzados con el respaldo gubernamental, sobre todo de los ministerios de Asuntos Exteriores y Cooperación, por un lado, y Defensa por el otro (Valero, 2013).

En ese esfuerzo empresarial de las industrias españolas, respaldadas por el Estado, América Latina aparece como un mercado de interés para la colocación de producción. En rigor de verdad, el mercado latinoamericano no era del todo desconocido para las empresas españolas, pues en otras épocas habían realizado importantes negocios con los países de la región. En 
este sentido, con anterioridad al fin de la Guerra Fría es probable que la principal venta de productos españoles para la Defensa haya tenido lugar en Chile y se haya desarrollado en el rubro aeronáutico. En las postrimerías de los años setenta, la empresa CASA vendió a la nación sudamericana una decena de aviones de transporte liviano C-212 Aviocar, firmando además un convenio de cooperación con la Empresa Nacional de Aeronáutica (ENAER) local.

Por medio de ese entendimiento, Chile adquirió tres reactores de entrenamiento C-101 Aviojet, bautizados en ese país como T-36 Halcón, acordando el ensamblaje en instalaciones propias de cerca de una quincena de aparatos adicionales, cantidad a la cual se agregó otra treintena de unidades a mediados de los años ochenta, con un porcentaje cada vez mayor de participación de componentes locales. Con una operatoria similar, ENAER ensambló cerca de una treintena de helicópteros BO-105 fabricados por CASA bajo licencia de la empresa alemana $\mathrm{MBB}$, destinados a la Fuerza Aérea chilena. Este vínculo interempresario perdura hasta el día de hoy, en que la estatal chilena elabora el conjunto posterior de los aviones de transporte CN-235 y CN-295 que fabrica el consorcio EADS-CASA.

Secundando a Chile, otros importantes compradores de la producción española, en ese decenio de los ochenta previo al inicio del proceso de fusiones y adquisiciones en el sector, fueron Argentina, México y Venezuela. Las adquisiciones argentinas se enmarcaron en lo que sin dudas fue su último programa integral de reequipamiento hasta la actualidad y consistieron básicamente en cinco patrulleros oceánicos clase Halcón construidos por la Empresa Nacional Bazán de Construcciones Navales Militares y asignados a la Prefectura Naval; como dato anecdótico, puede comentarse que en las gestiones que derivaron en la concreción de esta venta participó en forma personal el entonces Rey de España, Juan Carlos I.

México también adquirió durante el lapso mencionado seis patrulleros Halcón, un buque escuela bautizado Cuauhtemoc por su propietario y una decena de aeronaves de transporte. Los negocios con Venezuela, finalmente, incluyeron la modernización integral de casi un centenar de carros de combate AMX-30 de origen francés; la compra del buque escuela Simón Bolívar (construido, al igual que el caso mexicano, en los astilleros Celaya, de Bilbao); la adquisición de cuatro buques patrulleros clase Cormorán a la Empresa Nacional Bazán de Construcciones Navales Militares; por último, la incorporación de siete aviones de transporte.

Los cuatro países referidos, sumados a otros con compras cuantitativamente menores, colocaron a América Latina como el tercer mercado en importancia para los productos de España en ese rubro, tras Medio Oriente y el Maghreb, respondiendo por el $14 \%$ de su volumen de ventas globales. Discriminada esta actividad comercial por sectores, casi un 70\% correspondió a material naval y aeronáutico; otro $17 \%$ a armas livianas, artillería y municiones; y el $14 \%$ restante a material de transporte. Si el criterio de discriminación es por empresa, los ya mencionados astilleros Bazán (que luego formarían parte del consorcio Navantia) fueron responsables por aproximadamente un tercio de las operaciones, seguidos por la aeronáutica CASA; mientras los astilleros colocaron en la región casi una veintena de buques patrulleros de diferente tipo, la 
aeronáutica vendió ochenta y cinco aviones, armados o por armarse, discriminados en partes prácticamente iguales entre reactores de entrenamiento y aeronaves de transporte (Fisas, 1998).

Ya en el presente siglo, las ventas de material de Defensa a América Latina continuaron. Entre los años 2000 y 2009 la industria de Defensa española concretó negocios en América Latina por valor de € 646,8 millones. Un país que no figuraba en el listado de clientes en el decenio anterior, Brasil, se configuró en el principal comprador de este período, con adquisiciones equivalentes a € 266 millones; a continuación se posicionaron Chile con € 189 millones, Colombia (€ 94 millones), Ecuador (€ 56 millones), México (€ 44 millones) y Venezuela (€ 15 millones) (Ortega y Gómez, 2010).

Entre los productos del ámbito de la Defensa que España ha vendido en los últimos años a América Latina se incluyen, en un listado no exhaustivo, obuses de $155 \mathrm{~mm}$ a Colombia; aviones de transporte de tropas y de vigilancia a Brasil y México; vehículos blindados, fragatas y buques de patrullaje a Venezuela; lanzacohetes portátiles a El Salvador; y municiones, motores, repuestos y piezas a diferentes países. También se incluyen en este renglón productos tecnológicamente duales, como sustancias químicas para las industrias petrolífera y petroquímica, electrodos de grafito empleados en la siderurgia o sistemas de control numérico para maquinaria.

Cuadro 1. Adquisición de material de defensa de origen español durante el lustro 2005-2009 por países latinoamericanos seleccionados

\begin{tabular}{|c|c|c|}
\hline País & Concepto & Costo (US\$ millones) \\
\hline Bolivia & 1 avión C-212 & $\mathrm{S} / \mathrm{D}$ \\
\hline Brasil & 12 aviones $\mathrm{C}-295$ & 464 \\
\hline Colombia & $\begin{array}{l}4 \text { aviones C-295 } \\
1 \text { avión C-235 }\end{array}$ & $S / D$ \\
\hline \multirow{3}{*}{ Chile } & $\begin{array}{l}4 \text { patrulleras } \\
4 \text { corbetas }\end{array}$ & 1100 \\
\hline & $\begin{array}{l}10 \text { aviones } \mathrm{C}-295 \\
2 \text { aviones C-235 }\end{array}$ & 400 \\
\hline & 2 submarinos Scorpéne (con Francia) & 120 \\
\hline Ecuador & $\begin{array}{l}2 \text { aviones } \mathrm{C}-235 \\
2 \text { aviones } \mathrm{C}-212\end{array}$ & 84 \\
\hline México & 7 aviones C-295 & 110 \\
\hline Venezuela & $\begin{array}{l}4 \text { patrulleras oceánicas }(*) \\
4 \text { patrulleras costeras }\end{array}$ & 1600 \\
\hline
\end{tabular}

(*) Buques de Acción Marítima (BAM), según la nomenclatura del fabricante.

Fuente: elaboración propia con base a tablas 7 a 14 de Ortega \& Gómez (2010).

Por las particulares connotaciones políticas que generó, tanto en el ámbito doméstico español como en sus vínculos con EEUU, cabe efectuar una breve referencia a los navíos 
adquiridos por Venezuela. Esa operación fue acordada en enero de 2005 en Caracas por José Bono y Jorge García Carneiro, ministros de Defensa de España y la nación latinoamericana, respectivamente, como correlato de la visita oficial a Madrid que meses antes había efectuado Hugo Chávez, líder de la Revolución Bolivariana.

Las crónicas de ese episodio indican que el referido acuerdo generó profundos debates en el seno del gobierno español, entre las carteras de Defensa y Asuntos Exteriores: mientras la primera consideraba que la venta era de crucial importancia para el funcionamiento de los astilleros Izar (del conglomerado Navantia), la segunda sostenía que la operación era políticamente inconveniente pues repercutiría negativamente en el vínculo con la administración Bush, habida cuenta las conflictivas relaciones entre Washington y Caracas.

Efectivamente la Casa Blanca, durante dos años y medio (hasta mediados del año 2007), apelando a diferentes canales, hizo saber al Ejecutivo español su descontento con la venta de fragatas a Venezuela por cuanto contribuía a la consolidación en el poder de Chávez, así como una tácita legitimación de su retórica agresiva y belicista en el plano regional. En ese cometido, su principal aliado en el gobierno español parece haber sido Miguel Ángel Moratinos, titular de Asuntos Exteriores.

En sentido inverso, los argumentos a favor de la venta giraron en torno a dos o tres ejes claves, además del económico: que los buques no tenían una configuración ofensiva sino defensiva y de hecho no portaban misiles; que serían empleados para la vigilancia y protección de la Zona Económica Exclusiva venezolana y en tal sentido serían de utilidad en la lucha contra el tráfico de drogas y el terrorismo (objetivos declarados del gobierno estadounidense); adicionalmente que EEUU también vendía armamento a países con problemas regimentales como se verificaba en los casos (claramente no democráticos) de Arabia Saudita, Kuwait, Marruecos o Pakistán (Jiménez, 2010).

La operación finalmente se concretó y Venezuela recibió los ocho buques, a los que bautizó con nombres indígenas: Guaicaipuro, Warao, Yekuana y Kariña, en el caso de los patrulleros costeros; Guaicamacuto, Yavire, Naiguata y Tamanaco para los patrulleros oceánicos. Un navalista catalán que evidencia cierta identificación con los lineamientos del Palacio de Miraflores (Campanera i Rovira, 2013) le ha asignado ribetes épicos a este caso, resaltando que la posición sostenida por el ministro Bono rechazando las advertencias del embajador estadounidense en Madrid constituía la defensa de los intereses españoles en un mundo globalizado y de libre comercio.

En el presente decenio, el principal comprador de productos españoles de Defensa en América Latina es precisamente Venezuela. En el año 2012 el país caribeño efectuó adquisiciones de ese origen por € 182 millones, sólo superado por Australia con € 505 millones. Estas cifras significan que sobre los $€ 1953$ millones de ventas de material de Defensa realizadas por España en ese ejercicio anual, el régimen bolivariano fue responsable 
de casi el 10\%. Los gastos venezolanos se concentraron sobre todo en un patrullero naval de vigilancia, partes para el ensamblado de otro navío en astilleros locales, así como consumibles y repuestos para aviones y piezas de artillería (Agencia EFE, 2013).

Luego de resultados tan promisorios, es natural que España busque intensificar a corto y mediano plazos la colocación de su producción en el espacio latinoamericano. Así lo indicó a comienzos del presente año Pedro Meneses, titular de la cartera de Defensa española, quien resaltó la competitividad que en este rubro ostenta la industria nacional y las posibilidades de cooperación que el sector puede encontrar en América Latina, a la luz del incremento de la importancia de esta región en el tablero geopolítico mundial, gracias a su estabilidad política y su sostenido crecimiento económico.

El funcionario agregó, a modo de atractivo adicional, que las compras de material de Defensa a su país podían dar lugar al desarrollo del proceso productivo en el territorio del país comprador, con los benéficos efectos económicos que esto supone. En sus propias palabras: "la deslocalización como principio de gestión industrial es un elemento que se impone en el mundo y tiene un sentido no solamente de gestión económica de la propia empresa, sino también de apertura de mercados" (Agencia EFE, 2014).

\section{EMPLEO DEL INSTRUMENTO MILITAR EN INICIATIVAS QUE INVOLUCREN A LA CONTRAPARTE}

La participación de España en iniciativas que contemplen el empleo del instrumento militar e involucren a una o más naciones de América Latina presupone, desde el punto de vista cualitativo, una fuerte e intensa interacción entre esas partes, aun cuando pueda haber terceros actores estatales intervinientes. En esta esfera, existen diferentes acciones que merecen ser mencionadas, tres de las cuales se encuadran en las operaciones de paz de la Organización de las Naciones Unidas (ONU).

Hace un cuarto de siglo, ese organismo implementó el Grupo de Observación de la ONU para Centroamérica (ONUCA), seguido luego por la Misión de Observación para El Salvador (ONUSAL) y culminando con la Misión para Guatemala (MINUGUA). En los tres casos, el protagonismo de las Fuerzas Armadas de España fue particularmente alto.

Rastrear la génesis de la participación española en esas misiones permite establecer que el Poder Ejecutivo de ese momento, a la sazón encabezado por Felipe González, identificó como una eficaz estrategia de refuerzo del vínculo bilateral con las naciones centroamericanas el apoyo al proceso de paz que ellas estaban intentando llevar adelante, tal cual lo expresado en los tratados de Contadora y Esquipulas. El citado refuerzo de las relaciones con los países de América Central no sólo beneficiaría a España en términos de influencia, sino también a la contraparte bajo la forma de estabilidad política y desarrollo económico, y las Fuerzas Armadas eran percibidas como una herramienta idónea a ese doble efecto. 
De acuerdo al entonces ministro de Defensa español, Julián García Vargas, "la opinión pública, según las encuestas, apoya hoy decididamente las misiones de paz con cobertura de organismos internacionales reconocidos... haciendo hincapié en aquellas áreas donde la presencia española resulta más útil y apreciadas desde el punto de vista político y cultural, como ha sido el caso de nuestra labor en los países de Centroamérica". Efectivamente, los sondeos de opinión mostraban que el $68 \%$ de los ciudadanos se mostraba partidario de una política activa de participación en la resolución de los conflictos que aquejaban a esa región, porcentaje que ascendía hasta el 94\% si los consultados eran líderes políticos (Blázquez Vilaplana, 2002).

Más concretamente, a través de ONUCA el gobierno español le confió al área de Defensa la tarea de iniciar una nueva etapa de las Fuerzas Armadas, como un instrumento de la diplomacia que debía contribuir a una mejora de la imagen del país en el exterior (la mencionada Diplomacia de Defensa). Adicionalmente, este esfuerzo tenía un positivo efecto en el ámbito doméstico, mejorando la imagen de las instituciones castrenses y disociándolas de la época franquista (Moreno Izquierdo, 2010).

Cuadro 2. Opinión pública y Fuerzas Armadas en España.

\begin{tabular}{|l|c|l|c|}
\hline \multicolumn{2}{|c|}{$\begin{array}{c}\text { ¿Está usted de acuerdo o en desacuerdo con } \\
\text { que España participe de operaciones de paz? }\end{array}$} & \multicolumn{2}{c|}{$\begin{array}{c}\text { iConsidera que la actuación de las Fuerzas } \\
\text { Armadas ha contribuido a incrementar el } \\
\text { prestigio de España? }\end{array}$} \\
\hline \multicolumn{1}{|c|}{ Respuesta } & $\%$ & \multicolumn{1}{c|}{ Respuesta } & $\%$ \\
\hline De acuerdo & 91,9 & Mucho & 11,3 \\
\hline Desacuerdo & 4,8 & Bastante & 41,2 \\
\hline NS/NC & 3,3 & Poco & 25,5 \\
\hline TOTAL & 100 & Nada & 11,8 \\
\hline \multirow{2}{*}{} & & NS/NC & 10,2 \\
\cline { 2 - 4 } & TOTAL & 100 \\
\cline { 2 - 4 } & &
\end{tabular}

Fuente: adaptación de Tabla 1 de Chinchón Álvarez (2007) p.19.

Específicamente en cuanto a la primera de las tres misiones mencionadas, se constituyó mediante la Res. 644 del Consejo de Seguridad, dando lugar así al pedido de los presidentes de los países centroamericanos que intentaban la superación de los complejos conflictos armados que azotaban al istmo ${ }^{2}$. El rol desempeñado por España en esa misión fue crucial, en un doble sentido: en primer lugar, porque su primer comandante fue un general del ejército español (también lo sería el tercero, tras la jefatura de un canadiense), según el deseo expresado por los

2. Datos cuantitativos y cualitativos sobre la participación española en ONUCA, en la página oficial del Ejército de Tierra. Disponible en http://www.ejercito.mde.es/misiones/america/nicaragua/ONUCA.html 
mandatarios de la zona; en segundo término, porque de ese país procedió la mayoría de los observadores desplegados, exactamente cincuenta y siete efectivos sobre un total de doscientos sesenta, de una decena de naciones. De acuerdo al general Agustín Quesada Gómez, primer comandante de ONUCA, la preferencia de los centroamericanos por una conducción hispana de la misión obedecía a que ellos entendían la mentalidad, la idiosincrasia y la lengua del lugar (Blázquez Vilaplana, 2002).

El cuartel general se estableció en Tegucigalpa y los observadores se distribuyeron en una treintena de puestos de control diseminados en puntos específicos de los territorios costarricense, guatemalteco, hondureño, salvadoreño y nicaragüense. Su misión consistió en verificar el cese de la ayuda a los movimientos insurgentes, y controlar que el territorio de ningún Estado se utilizara con fines logísticos para atacar a bienes y personas ubicados en otro. Adicionalmente, a través de un plan llamado Home Run se monitoreó el proceso de desarme, concentración en zonas seguras y desmovilización de la resistencia (la llamada contra) nicaragüense. En este último punto la responsabilidad del comando español fue enorme en términos de credibilidad, pues debió garantizar a los desmovilizados su seguridad personal y que los sandinistas no llevarían a cabo represalias de ningún tipo (Moreno Izquierdo, 2010).

Las labores de esta misión multinacional se prolongaron hasta 1992, solapándose por pocos meses con la ya mencionada ONUSAL. Esta iniciativa apuntó a verificar la aplicación de los acuerdos alcanzados por el gobierno y la insurgencia del Frente Farabundo Martí para la Liberación Nacional (FMLN) en materia de desarme, desmovilización, desmilitarización, pacificación social y consolidación democrática, entre otras cuestiones. La Misión fue establecida por la Res. 693 del CSNU, del 20 de mayo de 1991 y se prolongó hasta el 30 de abril de 1994, tras la finalización exitosa del proceso electoral local.

Junto con España, participaron de ONUSAL en sus diferentes fases otras siete naciones (Brasil, Chile, Colombia, Guyana, Italia, México y Venezuela), aunque claramente el contingente español fue el más numeroso. Sobre una treintena de observadores estructurados en una División de Derechos Humanos, la mitad eran españoles. La División Militar, integrada por una quincena de oficiales de las Fuerzas Armadas que se desempeñaban como enlace entre las partes signatarias, contaba con cinco españoles y era dirigida por un comandante propio, el general Víctor Suanzes. Además, esa división se completaba con 380 observadores encargados de verificar el cese de fuego; de los cuales casi ciento cuarenta procedían de España. Un tercer pilar de esta iniciativa multinacional, la División Policial, contó con cuatro guardias civiles y otros tantos policías españoles, sobre quince miembros totales ${ }^{3}$.

3. Datos cuantitativos y cualitativos sobre la participación española en ONUSAL, en la página oficial del Ejército de Tierra. Disponible en http://www.ejercito.mde.es/misiones/america/salvador/ONUSAL.html 
La trilogía de misiones multinacionales desarrolladas en el área mesoamericana y que contaron con una participación central de España se completó con MINUGUA ${ }^{4}$. Desde el punto de vista cuantitativo fue la más reducida de las tres, aunque la de mayor duración pues se prolongó 8 años. Su inicio data de agosto de 1994, el despliegue de observadores comenzó dos meses más tarde y culminó el 31 de diciembre de 2002. Durante su transcurso, en diciembre de 1996 el gobierno y la antigua guerrilla Unión Revolucionaria Nacional Guatemalteca (URNG) concluyeron el conflicto armado comenzado en 1960 y que en todo su transcurso provocó unos 150 mil muertos, más de 45 mil desaparecidos y 1 millón de desplazados.

Bajo mando de un general español, ese alto el fuego dio lugar a un complejo proceso de desarme, desmovilización y reconciliación nacional. La misión contó con un total de 400 miembros, entre ellos 17 oficiales militares, 7 de ellos españoles; además disponía de 53 observadores policiales, 17 de ellos procedentes de la Guardia Civil de España.

Hacia fines del año 1998 volvieron a repetirse los altos niveles de coparticipación de España y las naciones centroamericanas, registrados en las misiones multinacionales ONUCA, ONUSAL y MINUGUA. Aunque en esa ocasión, el perfil de lo actuado fue absolutamente diferente, a tono con el evento que operó como detonante: el azote sobre los territorios de Guatemala, Honduras, El Salvador y Nicaragua del huracán Mitch, que dejó en la zona un alto saldo de muerte y destrucción. De acuerdo a cálculos de la Comisión Económica para América Latina (CEPAL), ese fenómeno climático mató a 11 mil personas, causó la desaparición de otras 9 mil, motivó el desplazamiento de 1 millón y afectó de una u otra manera a casi 7 millones de centroamericanos, más del $23 \%$ de la población total de los 4 países; por otro lado, en términos económicos, causó pérdidas superiores a US\$ 5 mil millones. Diría en esos momentos César Gaviria, Secretario General de la Organización de Estados Americanos (OEA): "El legado del huracán es tan dramático como el de una guerra, tanto por la destrucción de su infraestructura y el daño al tejido social como por el resurgimiento de amenazas al sistema democrático" (Fonseca, 1998, p.1).

Frente a esa tragedia España adoptó unilateralmente una batería de medidas de diferente tenor, entre ellas una condonación parcial de deuda a las 4 naciones afectadas. Pero su decisión más trascendente fue de naturaleza humanitaria y se canalizó a través del instrumento militar. En ese sentido, se llevó adelante lo que hasta ese momento fue el mayor despliegue de sus Fuerzas Armadas en el extranjero: más de un millar de efectivos; los buques Galicia, Pizarro y Hernán Cortés; catorce aviones de transporte y la unidad de ingenieros Salamanca del Ejército de Tierra, acantonada en tiempos de paz en la ciudad del mismo nombre y en Sevilla.

Esa unidad de ingenieros estuvo desplegada en el área mesoamericana entre diciembre de 1998 y abril del año siguiente, lapso en el cual tendió dos puentes tipo Bailey (uno de ellos en la

4. Datos cuantitativos y cualitativos sobre la participación española en MINUGUA, en la página oficial del Ejército de Tierra. Disponible en http://www.defensa.gob.es/areasTematicas/misiones/historico/misiones/mision_37.html 
frontera entre Nicaragua y Honduras y el otro sobre el Río Juticalpa en Honduras); reconstruyó un centenar de kilómetros de carreteras; realizó trabajos de tendido y reparación de redes de alumbrado y saneamiento; prestó atención médica a más de 2 mil personas y colaboró en la distribución de 250 toneladas de ayuda humanitaria ${ }^{5}$.

En este plano, merece una referencia especial la conformación, bajo iniciativa y liderazgo español, de una unidad combinada integrada por efectivos de ese país y varias naciones de América Latina que se desplegó durante 10 meses en Irak, en el marco de las operaciones desarrolladas en su territorio tras los atentados terroristas del 11 de septiembre de 2001. Se la denominó Brigada Multinacional Plus Ultra y constituyó la primera gran unidad bajo mando español que ha actuado en misiones internacionales, al incorporar contingentes de Honduras (370 efectivos integrando el Batallón Expedicionario Xatruch), El Salvador (casi 400 efectivos organizados en el Batallón Cuscatlán), Nicaragua (una Fuerza de Tareas de Ayuda Humanitaria de 115 efectivos) y República Dominicana (300 efectivos nucleados en la Fuerza de Tareas Quisqueya).

El planeamiento de las operaciones que luego desarrollaría la Brigada comenzó en marzo del año 2003, inmediatamente después de celebrada en las Islas Azores la cumbre en la cual el mandatario español José María Aznar confirmó ante su homólogo estadounidense George Bush que participaría de la coalición internacional liderada por EE. UU. contra las Fuerzas Armadas iraquíes, que respondían todavía a Sadam Hussein. La unidad comenzó a desplegarse a mediados de ese año, luego de haber sido aprobado por el Consejo de Ministros español, en la zona de Nayaf y Al-Diwaniyah, en el tercio meridional del país. Su encuadre era la División Multinacional Centro-Sur de la coalición, cuyo liderazgo era ejercido por Polonia, quien además encabezó otra brigada multinacional, mientras Ucrania hacía otro tanto.

El ejército español les proporcionó a los contingentes hispanoamericanos que integrarían la Brigada un período de instrucción y adiestramiento previo, que se llevó a cabo en sus instalaciones en San Clemente de Sasebes (Gerona). No obstante este recaudo, en un informe oficial publicado sobre los primeros tramos de esa iniciativa multilateral (BMNPU, 2004) se puso de relevancia el enorme desafío que supuso la integración exitosa de "unidades procedentes de naciones con intereses distintos, con doctrinas diferentes, con niveles de instrucción y adiestramiento dispares, con grados de adaptación al medio y con condiciones atmosféricas en absoluto iguales".

La Brigada, tras una rotación de personal (dando lugar a la Plus Ultra II), se mantuvo en la nación árabe hasta mayo del 2004, dos meses después de las elecciones nacionales que arrojaron como vencedor al Partido Socialista Obrero Español (PSOE), cuyo candidato José Luis Rodríguez Zapatero ordenó el repliegue luego de acceder al poder. En aquellos momentos

5. Datos cuantitativos y cualitativos sobre la participación española frente al huracán Mitch, en la página oficial del Ejército de Tierra. Disponible en http://www.ejercito.mde.es/misiones/america/honduras/MITCH.html 
llegó a decirse que la nueva postura gubernamental constituía una suerte de abdicación frente al flagelo terrorista internacional, teniendo en cuenta que en vísperas de esos comicios había acontecido el atentado perpetrado contra una formación férrea en cercanías de la estación madrileña de Atocha. Esa agresión, conocida normalmente como 11-M (por su ocurrencia el 11 de marzo) fue ejecutada por una célula de la organización Al Qaeda con ramificaciones locales y habría sido una represalia por el despliegue militar español en Afganistán e Irak. Como correlato de ese atentado, la opinión pública se expresó por abrumadora mayoría a favor del retiro de España de suelo iraquí.

Sin embargo, la retirada española de Irak no se explica a partir del 11-M (aunque el impacto de ese luctuoso ataque en la opinión pública no puede haber sido desestimado) sino por la exigencia de cumplimiento de dos condiciones para el mantenimiento de las tropas que habían sido anunciadas ya en la campaña electoral y que hasta ese momento no se alcanzaron: que la ONU asumiera la dirección política de Irak, y que las tropas estadounidenses sean colocadas bajo el mando del máximo organismo internacional o de cualquier otra organización supranacional (Batalla, 2004).

Resulta útil agregar aquí que los debates y contrapuntos suscitados por el polémico despliegue militar de España en Irak influyeron de manera directa en la Ley Orgánica 5/2005 de la Defensa Nacional sancionada al año siguiente. Este instrumento jurídico introduce una serie de consideraciones acerca de las misiones en el exterior, entre ellas el necesario sustento que deben poseer, proporcionado por una petición expresa del gobierno del Estado en cuyo territorio se desarrollen, o por una resolución del CSNU; que sean conformes con la Carta de la ONU y no contradigan ni vulneren los principios del derecho internacional y que cuenten con una autorización expresa del Congreso de los Diputados, en aquellos casos en que no esté directamente afectada la defensa de España o el interés nacional. Ninguno de estos tres requisitos se cumplió en el caso de marras (Muleiro, 2006).

Conviene en este punto efectuar una doble aclaración. Por un lado, que aunque España integró a los contingentes de los cuatros países centroamericanos en su fuerza, tornándola en multinacional, Madrid estuvo absolutamente al margen de las evaluaciones y negociaciones que culminaron con la decisión de los gobiernos de esas naciones de enviar tropas a Irak. Tal decisión fue el corolario de convenios que llevaron los Ejecutivos de esos países con la Casa Blanca, y cuyo alcance excede los objetivos del presente trabajo. Por otra parte y no menos importante, los contingentes centroamericanos no tenían la obligación de replegarse de Irak junto con la partida de sus camaradas españoles y la consecuente disolución de la Brigada Plus Ultra, pudiendo reubicarse en otros sectores y bajo nuevas cadenas de mandos, si sus respectivos gobiernos así lo decidían. El Salvador, por ejemplo, permaneció en suelo iraquí hasta el 31 de diciembre del año 2008 con un saldo de cuatro efectivos muertos en combate.

No resulta llamativo que tras la enriquecedora experiencia de la Brigada Plus Ultra, seis meses después de su finalización, España haya propuesto la constitución de una Fuerza Iberoamericana 
de Paz, a ser empleada en misiones de ese tipo organizadas por la ONU. Aunque la vinculación entre ambas cuestiones se presenta particularmente nítida, Del Arenal se orienta a relacionar la iniciativa española con su participación junto a numerosas naciones latinoamericanas en la Misión de la ONU de Estabilización de Haití (MINUSTAH), destinando a ese país caribeño unos doscientos efectivos (que integraron un contingente combinado con otros tantos uniformados marroquíes) (del Arenal, 2005). Sin embargo, en contra de este argumento debe decirse que en esa operación no se registraron niveles de conjuntez especiales entre las tropas españolas y las de América Latina.

La ocasión para lanzar la idea de la Fuerza se presentó en la XIV Cumbre Iberoamericana de Jefes de Estado y de Gobierno, celebrada en noviembre de 2004 en Costa Rica, y es justo decir que no parece haber gozado del apoyo necesario. De hecho, no hay mención a esta propuesta en la Declaración de San José, documento final del cónclave, pese a que su quinto punto alude al fortalecimiento del multilateralismo a través de las Naciones Unidas y la optimización del papel que le corresponde a este organismo en la salvaguarda de la paz y la seguridad internacionales; tampoco hay referencias a la unidad militar multinacional en la casi veintena de comunicados especiales que también emitió la Cumbre (OEI, 2004).

La realidad indica que falta de resultados concretos a la propuesta presentada en la Cumbre Iberoamericana no hizo desistir a España de explorar formas de coparticipar con las naciones latinoamericanas en iniciativas multilaterales que involucren las instituciones castrenses. Así en el año 2007, al tiempo que promovía otras iniciativas en materia de Defensa aunque de tinte educativo $^{6}$, se incorporó con carácter de observador permanente a la Junta Interamericana de Defensa (JID), organismo existente desde épocas de la Guerra Fría. Sobre esta incorporación, se ha opinado (Raggio Cachinero, 2007) que la Junta puede-y debe- servir de vía de acercamiento de España a las iniciativas de cooperación en materia de seguridad que se desarrollan en el continente, considerando que ambos planos de actividad no son incompatibles; o puede constituirse en una importante fuente de información sobre las prioridades hemisféricas en materia de Defensa, seguridad y Fuerzas Armadas, orientando en este campo las acciones cooperativas españolas, que se canalizarían bilateralmente o en el marco de las cumbres multilaterales (González, 2007).

\section{CONCLUSIÓN}

América Latina ocupa un lugar prioritario dentro del contexto de la política exterior de España, sustentado en razones de índole histórica y cultural. Esa posición privilegiada se ha mantenido inalterable a lo largo del tiempo, más allá de algunos ajustes, como

6. Por esos momentos España comenzó a impulsar la creación de un Colegio Iberoamericano de Seguridad y Defensa de modalidad virtual (a distancia). Esa iniciativa fue oficialmente plasmada en el texto oficial de la Cumbre Iberoamericana celebrada en noviembre de ese año en Santiago de Chile. 
los efectuados al momento del ingreso en la Comunidad Europea; o de la aparición de fricciones aisladas, como aconteció en oportunidad del apoyo a EEUU para intervenir militarmente en Irak.

Los ámbitos en los que se despliega el involucramiento de España en los asuntos latinoamericanos son múltiples y por cierto incluyen al de la Defensa. Aunque la vinculación entre las partes en este aspecto específico dista de ser novedosa, a lo largo de la última década ha sido ratificada a través de las Directivas de Defensa emitidas en los años 2004 y 2008 respectivamente.

En este marco de relacionamiento, que se corresponde con el concepto de Diplomacia de Defensa, en el espacio latinoamericano se observa una constante comercialización de material bélico español, el cual se respalda en un sector industrial con alto grado de desarrollo tecnológico, claro perfil exportador y un nítido apoyo estatal, en materia de orientación y financiación.

Hoy América Latina constituye un importante mercado para la colocación de productos españoles para la Defensa (particularmente material aeronáutico y naval), con promisorias oportunidades de crecimiento y Madrid se erige en un proveedor confiable, según se desprende de su posición frente a las presiones ejercidas por EEUU en relación a la venta de buques a Venezuela.

La coparticipación en iniciativas multilaterales que contemplen el empleo del instrumento militar ha sido otro plano donde España desplegó su involucramiento en cuestiones latinoamericanas. En tressituaciones diferentes, que obedecieron a otrastantas circunstancias, América Central constituyó la región hacia donde se orientaron principalmente los esfuerzos del país europeo.

El involucramiento de la comunidad internacional en la resolución de las sangrientas guerras civiles que azotaban al istmo sirvió de marco para que España se consolidara como el protagonista clave de las tres misiones de paz que se ejecutaron en esa zona entre los años 1989 y 2002. Una evaluación retrospectiva sobre estos casos confirma que España aportó la mayoría de los efectivos desplegados, así como de los máximos comandantes militares, ejerciendo un liderazgo clave en su desenlace exitoso.

También en términos retrospectivos cobra trascendencia la respuesta española en ocasión del huracán Mitch, desde el momento en que derivó en su mayor despliegue de efectivos militares en el extranjero con fines humanitarios llevado a cabo hasta ese momento. El reconocido prestigio internacional que hoy ostenta España en este campo, cimentado en múltiples operaciones llevadas a cabo en todo el globo, se sustenta en buena medida en la experiencia adquirida a partir del desastre natural centroamericano. 
Lo sucedido en la guerra de Irak, donde las tropas centroamericanas que participaron de esa contienda se incorporaron a una unidad española, que se configuró así en multinacional, constituye el antecedente más importante de accionar combinado entre países latinoamericanos y europeos en circunstancias reales, en lo que va del presente siglo. La importancia de la experiencia adquirida explica la iniciativa presentada por España tiempo más tarde, de conformar una Fuerza Iberoamericana de Paz, lo que a su vez indica su intención de no circunscribir su presencia a la zona centroamericana.

No obstante su importancia, lo visto hasta aquí no agota el campo de posibilidades de vinculación que ofrece la Defensa, para las relaciones entre España y América Latina. Esta apreciación se fundamenta en dos elementos centrales: primero, que ni la comercialización de material bélico español en el espacio latinoamericano, ni la coparticipación de Fuerzas Armadas de las partes en iniciativas multilaterales, parecen haber llegado al límite de las posibilidades; segundo, que más allá de estas manifestaciones existen otros espacios para la cooperación en esta esfera, muchos de ellos en desarrollo.

\section{REFERENCIAS}

Agencia EFE (2013). “Venezuela fue el principal destino en Latinoamérica de armas españolas en 2012", América Economía 6 de septiembre. Recuperado de http://www.americaeconomia. $\mathrm{com} /$ politica-sociedad/politica/venezuela-fue-el-principal-destino-en-latinoamerica-dearmas-espanolas-en.

(2014). "Ven en América Latina un gran potencial para la industria de defensa española", América Economía 15 de marzo. Recuperado de http://www.americaeconomia. $\mathrm{com} /$ politica-sociedad/politica/ven-en-america-latina-un-gran-potencial-para-la-industriade-defensa-espa.

Aznar, F. (2012). La Ecuación de la Guerra, Madrid, Montesinos, 191-192.

Batalla X (2004). “Algo más que una promesa”, Real Instituto Elcano, ARI 83, 29 de abril.

Blázquez Vilaplana, B. (2002). "La participación española en las operaciones de paz en Centroamérica", Congreso Nacional de Estudios de Seguridad, Universidad de Granada, 21 de octubre.

BMNPU (2004). “Documento: Brigada Plus Ultra. Una labor para la eficacia”, Ejército 756, 40.

Calduch Cervera, R. (2002). La Política Exterior de España. Balance y Perspectivas, Madrid, Fundación Global Democracia y Desarrollo. 
Campanera i Rovira, A. (2013). "Armada Venezolana versus Marina Bolivariana", Fuerzas de Defensa y Seguridad 419.

Chinchón Álvarez, J. (2007). "Cooperación en materia de enseñanza/formación militar entre España y los Estados de Iberoamérica", Observatorio de Política Exterior Española (OPEX), Documento de Trabajo 13.

Del Arenal, C. (2004). "La Política Exterior del gobierno socialista", Política Exterior 100, 111-126.

(2005). "De la Cumbre Iberoamericana de San José de Costa Rica (2004) a la Cumbre Iberoamericana de Salamanca (2005)", Real Instituto Elcano, Documento de Trabajo 5.

Fisas, V. (1998). "Las exportaciones españolas de armamento a América Latina durante la década del 80", Afers Internacionals 14-15, 41-62.

Fonseca, R. (1998). "Huracán Mitch tuvo el efecto de una guerra", Boletín Inter-Press Service, 12 de diciembre. Recuperado de http://www.ipsnoticias.net/1998/12/boletin-integracionamerica-central-huracan-mitch-tuvo-el-efecto-de-una-guerra/

Fuente Cobo, I. (2007). "La cooperación militar española con los países iberoamericanos". En CESEDEN, Seguridad y Defensa en Iberoamérica: posibilidades actuales para la cooperación, Madrid, Ministerio de Defensa, 50-62.

Fundación Carolina (2011). Debate. Política Exterior de España y relaciones con América Latina, Madrid, Fundación Carolina.

García Covarrubias, J. (2005). "La Transformación de la Defensa: el caso de EE.UU. y su aplicación en América Latina", Military Review (edición en español), marzo-abril, 23-30.

González, J. (2007). "España y la convergencia iberoamericana en materia de Defensa". En CESEDEN, Seguridad y Defensa en Iberoamérica: posibilidades actuales para la cooperación, Madrid, Ministerio de Defensa, 35-49

Grasa Hernández, R. (2001). "La política exterior española hacia América Latina: tendencias recientes y proyección hacia el futuro", Revista CIDOB d'Afers Internacionals 54-55, 65-83.

Gratius, S. (2010). “¿Por qué España no tiene una política hacia América Latina?”, FRIDE Policy Brief 24. 
Jiménez, M. (2010). "La venta de barcos a Chávez dividió al gobierno español", El País 9 de diciembre. Recuperado de http://internacional.elpais.com/internacional/2010/12/08/ actualidad/1291762815_850215.html.

Méndez C., et.al. (2013). "La industria de Defensa en España y sus capacidades tecnológicas", Observatorio de Política Exterior Española (OPEX), Documento de Trabajo 74.

Michou, H. y Torreblanca, J. (2013). “Diplomacia, desarrollo y defensa en la política exterior española", EsGlobal, 22 de julio.

Ministerio de Defensa de España (2011). Plan de Diplomacia de Defensa, Madrid, Ministerio de Defensa.

Moreno Izquierdo, R. (2010). "Veinte años de la paz de ONUCA", Revista Española de Defensa, julio-agosto, 50-54.

Muleiro, V. (2006). "Militares españoles en el extranjero", El Siglo de Europa 708, 18 de septiembre. Recuperado de http://www.elsiglodeuropa.es/siglo/historico/2006/708/708dossier.html.

Organización de Estados Iberoamericanos (2004). XIV Cumbre Iberoamericana de Jefes de Estado y de Gobierno. Declaración de San José, San José, 20 de noviembre. Recuperado de http://www.oei.es/xivcumbredec.htm.

Ortega, P. y Gómez, J. (2010). Militarismo en América Latina, Barcelona, Justicia i Pau.

Raggio Cachinero, B. (2007). "Cooperación Iberoamericana en materia de Defensa". En Sepúlveda I. (editor), Seguridad Humana y Nueves Perspectivas de Defensa en Iberoamérica, Madrid, Instituto Universitario General Gutiérrez Mellado - UNED, 577-600.

Valero, L. (2013). "El compromiso del Ministerio de Industria con la internacionalización de la industria española de la defensa". En IDS, Spain Defense and Security 2013, Madrid, IDS, 9.

"Vocación Iberoamericana". Página web oficial del Ministerio de Defensa de España, s/f. Recuperado de http://www.defensa.gob.es/politica/seguridad-defensa/contexto/ iberoamericana/. 